
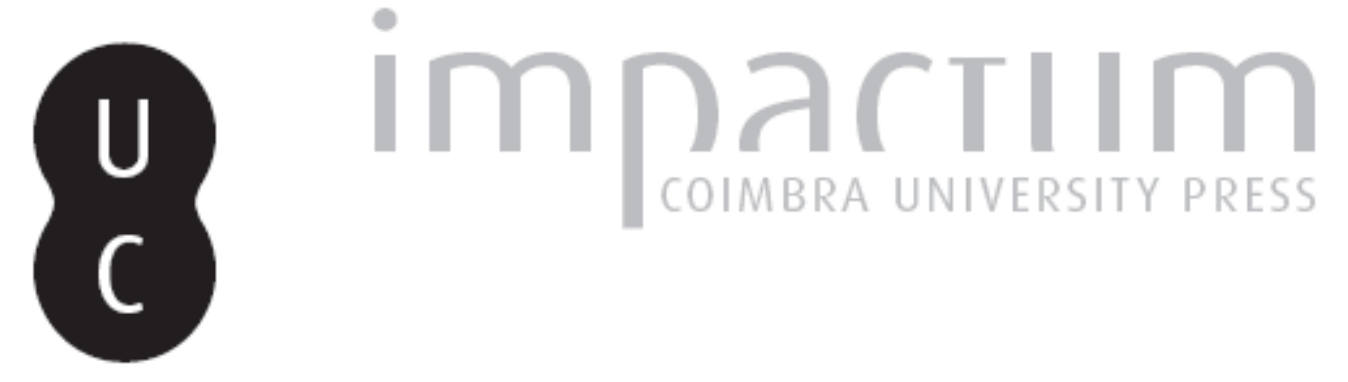

\title{
O nordeste alentejano ao tempo dos Romanos: balanço e perspectivas da investigação
}

\author{
Autor(es): D’Encarnação, José
}

Publicado por: Imprensa da Universidade de Coimbra

URL

persistente:

URI:http://hdl.handle.net/10316.2/45525

DOI:

DOI:https://dx.doi.org/10.14195/1647-8657_30_3

Accessed : $\quad$ 26-Apr-2023 10:44:51

A navegação consulta e descarregamento dos títulos inseridos nas Bibliotecas Digitais UC Digitalis, UC Pombalina e UC Impactum, pressupõem a aceitação plena e sem reservas dos Termos e Condições de Uso destas Bibliotecas Digitais, disponíveis em https://digitalis.uc.pt/pt-pt/termos.

Conforme exposto nos referidos Termos e Condições de Uso, o descarregamento de títulos de acesso restrito requer uma licença válida de autorização devendo o utilizador aceder ao(s) documento(s) a partir de um endereço de IP da instituição detentora da supramencionada licença.

Ao utilizador é apenas permitido o descarregamento para uso pessoal, pelo que o emprego do(s) título(s) descarregado(s) para outro fim, designadamente comercial, carece de autorização do respetivo autor ou editor da obra.

Na medida em que todas as obras da UC Digitalis se encontram protegidas pelo Código do Direito de Autor e Direitos Conexos e demais legislação aplicável, toda a cópia, parcial ou total, deste documento, nos casos em que é legalmente admitida, deverá conter ou fazer-se acompanhar por este aviso.

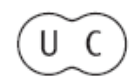


FACULDADE DE LETRAS

INSTITUTO DE ARQUEOLOGIA

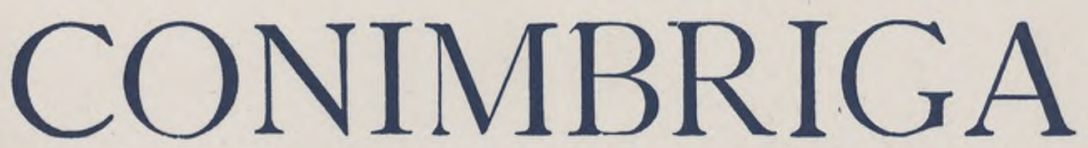

VOLUME XXX

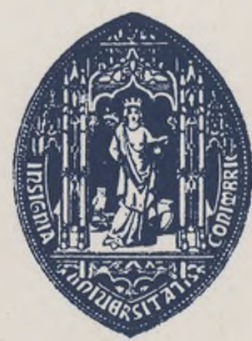

UNIVERSIDADE DE COIMBRA 


\section{José D'ENCARNAÇÃo}

Professor catedrático da Faculdade de Letras da Universidade de Coimbra

\section{O NORDESTE ALENTEJANO AO TEMPO DOS ROMANOS - BALANÇO E PERSPECTIVAS DA INVESTIGAÇÃO}

«Conimbriga» XXX (1991), p. 23-37

RESUmo: Tem sido parcelar, fragmentário e incompleto o estudo da ocupação romana no Nordeste alentejano: das suas riquíssimas villae mal se conhece a planta, o espólio jaz por estudar na sua quase totalidade; no âmbito das necrópoles, ora se começam a dar os primeiros passos, com resultados surpreendentes; das vias que percorriam a região não se fez ainda no terreno o seu levantamento exaustivo.

Apresenta-se, neste artigo, uma panorâmica do que já se estudou e apontam-se perspectivas para a futura investigação.

ABSTRACT: A study of Roman occupation in the north-east of the Portuguese country named Alentejo (Conventus Pacensis, Lusitania) has been to the present time parcelled, fragmentary and incomplet. The plants of their very rich villa are almost unknown, their furniture nearly unstudied; the analysis of Roman necropoles is just beginning, with surprising results; the complete regional net of roads is still locally indefinite.

This report presents a view of studies already done and points the future research perspectives. 
(Página deixada propositadamente em branco) 


\section{O NORDESTE ALENTEJANO AO TEMPO DOS ROMANOS — BALANÇO E PERSPECTIVAS DA INVESTIGAÇÃO *}

As villce

Das riquíssimas villce existentes no Nordeste alentejano foram os mosaicos (parece) que mais atraíram a atenção dos arqueólogos: mal se lhes conhece a planta, o espólio jaz por estudar na quase totalidade; não se publicaram circunstanciados relatórios dos trabalhos desenvolvidos; desconhece-se, por exemplo, quantas villce há em cada uma, ou seja, quantas fases de ocupação nelas se poderão determinar ${ }^{\wedge}$ ).

De facto, falar do período romano no Nordeste leva-nos logo a pensar nas villce: Torre de Palma, Santa Vitória do Ameixial... Poucos nos lembraremos, por exemplo, da villa da Granja (Mártires, Crato). No entanto, ela foi a primeira duma série que Manuel Heleno pensara em publicar sistematicamente (1953). Em Fevereiro de 1936 aí estivera e vira cinco mosaicos geométricos, polícromos, de que apresenta fotografias, acrescentando:

«Aguardam a sua exploração e estudo» (p. 260).

Até hoje.

* Este artigo constitui, na sua essência, o texto da comunicação apresentada em Monforte, a 23 de Abril de 1989, por ocasião das II Jornadas de Arqueologia do Nordeste Alentejano. De então para cá, o panorama da Arqueologia romana na região sofreu algumas alterações, pelo que se introduziram aqui e ali as convenientes actualizações, acrescentaram-se notas de rodapé e fizeram-se as adaptações mais ajustadas a uma versão destinada a ser publicada fora do contexto das actas das Jornadas, para que fora inicialmente pensada.

(9 As escavações levadas a efeito, por exemplo, na villa romana de São Cucufate (Vidigueira), deram a conhecer para o mesmo local três fases de ocupação distintas: a villa I, que se designou de «quinta-celeiro»; a villa II, "villa de peristilo»; e a villa III, « a villa àulica do século IV» — vide Alarcão/Étienne/Mayet 1990. 
De resto, a série só teve mais uma villa, a de Torre de Palma (Heleno 1962).

De Torre de Palma conhecem-se, sobretudo, os mosaicos retirados para o Museu Nacional de Arqueologia, de Lisboa: o dos cavalos, as cenas dionisíacas... (cf. IRCP 603 e Kuznetsova-Resende 1989).

Decorria, por ocasião das I Jornadas de Arqueologia do Nordeste Alentejano (1985), uma campanha luso-americana que visava estudar o espólio osteológico e os vestígios do período post-romano ali ainda patentes, nomeadamente a basílica paleocristã. Os resultados terão excedido as expectativas, como se pode ver no primeiro relatório já apresentado $\left({ }^{2}\right)$.

De Santa Vitória do Ameixial, registe-se o enorme interesse dos mosaicos com as suas representações: os pontos cardeais aí vêm simbolizados nos quatro ventos-Eurus, Notus, Zephyrus e Boreas-numa gramática decorativa tipicamente clássica. A cena da mulher a ser fustigada tem dado azo a interpretações variadas (cf. IRCP 481). O tema mitológico de Ulisses a ser tentado pelas sereias é mais uma prova da absorção plena duma vivência cultural que se alardeia( $\left.{ }^{3}\right)$.

Em Alter do Chão, depois dos trabalhos efectuados em Ferragial d'El-Rei( $\left.{ }^{4}\right)$, em 1957, por membros do Instituto de Arqueologia da

(2) No relatório de actividades do então Serviço Regional de Arqueologia do Sul (actual Divisão de Arqueologia da Direcção Regional de Évora do Instituto Português do Património Cultural), referente ao ano de 1989, alude-se ao projecto de investigação em curso nesta villa por iniciativa da ProF. Stephanie Malloney da Universidade de Louisville (USA), que, de resto, apresentou em Monforte uma comunicação sobre a basílica paleocristã da villa e uma outra em que descreveu nove bronzes do Baixo Império aí exumados durante os trabalhos. Nesse projecto de valorização do sítio (vide Património, p. 15) se integram igualmente as sondagens realizadas por Maria da Luz Velloso da Costa Huffstot, que também interveio nas Jornadas de Monforte, e a execução do projecto de cobertura da chamada «Casa do Peristilo». Foi por Torre de Palma que se iniciou, em 1991, o programa de estudo global dos mosaicos romanos do conventus Pacensis, da responsabilidade das Dr. as Janine Lancha (da Universidade de Lyon - França) e Adília Alarcão (do Museu Monográfico de Conimbriga).

$\left.{ }^{3}\right)$ No relatório citado na nota anterior, apenas se aponta, na p, 11, a consolidação de mosaicos como trabalho desenvolvido, em 1989, na villa de Santa Vitória do Ameixial; mas o relatório de 1991 já fala da «execução do caderno de encargos para lançamento de empreitada de limpeza e ordenamento geral das ruínas e zona envolvente» (p. 7).

$\left(^{4}\right)$ Como adiante se indicará, Alter do Chão poderá ter sido um núcleo populacional de certa importância, transcendendo a simples villa. Só uma concer-

Conimbriga, 30 (1991), 23-37 
Faculdade de Letras da Univerdade de Coimbra, de que não se chegou a publicar circunstanciado relatório, a actividade de Brazão Ferreira e da sua equipa (1978) merece destaque. Além do Ferragial d'El-Rei, identificaram-se e estudaram-se vestígios romanos na Quinta do Pião. A actividade prosseguiu aí também em 1982 e 1983: exumou-se um mosaico polícromo, identificou-se a área residencial e os balneários (cf. IA 5 89-90)... E novos trabalhos se prevêem para breve neste concelho( $\left.{ }^{5}\right)$.

Na Quinta do Ribeiro da Nata, freguesia de Belver, concelho de Gavião, trabalhou Rogério Carvalho em 1983 (cf. IA 5 93-95) e 1985 (cf. IA 7 55-57): distinguiu duas épocas de ocupação, uma no século I e outra dos séculos II/IV. Trata-se, no entender deste arqueólogo, de um «pequeno núcleo populacional, fortemente ruralizado».

Sobre Campo Maior, designadamente sobre a villa de S. Pedro, além das informações (ainda inéditas) dadas a conhecer através das comunicações feitas às II Jornadas do Nordeste Alentejano, outros sítios se detectaram já, a confirmar a enorme riqueza arqueológica deste concelho( $\left.{ }^{6}\right)$.

Para servir as villoe e, também, os aglomerados populacionais, edificaram os Romanos inúmeros 'aproveitamentos' hidráulicos — barragens, canais subterrâneos, aquedutos — de que a equipa do Prof. Carvalho Quiniela forneceu, em 1986, um primeiro inventário a considerar( ${ }^{7}$ ).

tada política de sondagens poderá, pois, trazer luz sobre o verdadeiro significado das ruínas postas a descoberto, por exemplo, em Ferragial d'El-Rei e nas suas proximidades.

(5) No relatório citado na nota 2, assinala-se, na p. 6, como trabalho desenvolvido em 1989, uma «intervenção junto à villa romana do Ferragial d'El-Rei, motivada pela construção duma piscina»; e o relatório de 1991 alude à realização, por aquela Divisão Regional, de «sondagens preventivas na área de implantação da futura Escola Técnico-Profissional de Agricultura» também em Ferragial d'El-Rei (p. 4).

${ }^{6}$ ) No relatório citado na nota 2, referem-se os «trabalhos de conservação de vestígios da pintura mural» (p. 11) existentes na villa de São Salvador e informa-se que foi elaborada uma proposta de financiamento integrável em planos comunitários de valorização do património (vide também Património, p. 16). Em 1991, a Divisão Regional fez aí uma «limpeza geral da estação, mudança da areia que cobria os pavimentos, remate de mosaicos, desenho de plantas» e preparou o processo de classificação do sítio (Relatório, pp. 3 e 7) a que já foi dado superior seguimento. Os seus técnicos foram igualmente chamados a fazer uma intervenção de emergência no Bairro Habitacional de São Pedro, a preparar a proposta de estudo do impacte arqueológico da Barragem do Abrilongo (p. 3) e a elaborar o programa museológico para o Núcleo de Arqueologia do Museu Municipal de Campo Maior (p. 8).

$\left.{ }^{7}\right) \mathrm{Na}$ citada obra de Carvalho Quiniela, João Cardoso e José Manuel Mascarenhas, referem-se, do Nordeste alentejano (pp. 53-70), as barragens romanas 


\section{As necrópoles}

No âmbito das necrópoles romanas, ora se começam a dar os primeiros passos, com revelações surpreendentes.

A necrópole de Santo André, em Montargil (Ponte de Sor), datável da segunda metade do século I - inícios do século II, escavada sob a responsabilidade do Instituto de Arqueologia da Faculdade de Letras da Universidade de Coimbra, talvez constitua excepção, porque o relatório dos trabalhos já foi publicado, no volume 20 (1981) desta revista.

$\mathrm{Na}$ necrópole da Laje do Ouro (Aldeia da Mata, Crato) escavou Helena Frade em 1982 e 1983 (cf. IA 5 92-93), que deu conta dos resultados dessas primeiras campanhas por ocasião das I Jornadas. Os trabalhos tiveram continuidade em 1988, com o maior interesse $\left({ }^{8}\right)$. Helena Frade e José Carlos Caetano registaram aí a persistência da prática da incineração em pleno século III, circunstância a relacionar com o que se documenta nas necrópoles de Eivas, datáveis de um período que vai desde os finais do século II até aos séculos III e IV, e cujo espólio cerâmico Jeannette Nolen estudou (1985).

A necrópole da Herdade dos Pombais, sita no concelho de Marvão, foi alvo das atenções de Isabel Cristina Fernandes em 1982,1983,1984 1985 (cf. IA 5 96-97, 6 56,7 60). Está já delimitada a sua extensão e, nas I Jornadas (1985), a arqueóloga apresentou o estudo do espólio exumado. Também se identificou a villa a que a necrópole pertencia: Isabel Fernandes definiu, em 1986, a zona de habitação e um compartimento rectangular

da Tapada Grande (Castelo de Vide), de Almarjão (Crato), do Muro, de Oliva, da Mourinha e de Moralves (todas estas em Campo Maior), do Carrão (Eivas) e da Represa (Gavião), esta última de origem romana não confirmada (pp. 108-113); o tanque, o canal subterrâneo e o aqueduto do Correio-Mor, em Eivas (pp. 132-134, 144 e 151); e o aqueduto de S. Salvador de Aramenha (p. 151). Já foi iniciado o processo de classificação da barragem da Tapada Grande como imóvel de interesse público.

$\left.{ }^{8}\right)$ Os resultados da campanha de 1988 foram apresentados nas II Jornadas do Nordeste Alentejano (vide adiante, p. 39-58) e o primeiro balanço do projecto de investigação ai desenvolvido acerca dos ritos funerários foi comunicado ao II Congresso Peninsular de História Antiga (Coimbra, 1990), tendo-se chamado a atenção, de modo especial, para alguns «pormenores importantes relativamente à arquitectura e materiais utilizados na construção das sepulturas e à colocação do espólio, que ajudam a precisar esses ritos» (vide Frade/Caetano, no preio).

Conimbriga, 30 (1991), 23-37 
com arcaria em tijolo - que será muito provavelmente o hipocausto das termas (cf. IA 8 63) - bem como diversos tipos de sepulturas. As investigações tiveram, porém, de ser suspensas, devido a dificuldades surgidas com os proprietários dos terrenos.

Acrescente-se ainda que, no decorrer de 1991, houve, por iniciativa da Divisão de Arqueologia (Direcção Regional de Évora de IPPC), escavações de emergência numa outra necrópole, classificada como «tardo-romana», em Carapeta, Avis.

\section{As vias}

Das vias que percorriam a região não se fez ainda no terreno o seu levantamento exaustivo.

Conhece-se, de longa data, a ponte de Vila Formosa sobre a Ribeira da Seda; detectaram-se os vestígios da calçada romana e diversos miliários na zona de Ponte de Sor, por onde, aliás, tanto André de Resende como, na sua peugada, Bernardo de Brito indicaram ser o traçado da via que, por Scallabis, seguia de Olisipo até Emerita. Entretanto, a placa que José Rafael da Silva e eu próprio estudámos (1990) vem confirmar não só esse trajecto como, e sobretudo, a eventual existência de uma antiga ponte no local, datável do reinado de Trajano.

Só agora, porém, se estudou, por exemplo, o miliàrio de Évora-Monte (IRCP 732) que data do ano 320, pois nele se mencionam os três Césares Valério, Licínio-o-Jovem e Constantino II, marco que Tùlio Espanca considerara homenagem a um... judeu converso do século XVI, de apelido Tinoco. Também só recentemente (Carvalho 1988) pôde entrar nos circuitos científicos o de Campo Maior, citado já nas Memórias Paroquiais de 1758 e dedicado muito provavelmente a Domiciano, bem como um outro, de Severo Alexandre (Encarnação 1988).

\section{As publicações}

No âmbito das I Jornadas, em 1985, Isabel Fernandes deu a conhecer, como já referimos, o espólio da necrópole da Herdade dos Pombais; Sálete da Ponte estudou as fíbulas dadas como provenientes de Torre de Palma; Maria Helena Simões debruçou-se sobre os vidros romanos guardados no Museu do Crato; Helena Frade e José Carlos 
Caetano falaram das primeiras campanhas na Laje do Ouro; eu próprio tentei uma síntese acerca da população romana do Nordeste alentejano.

No comentário que, em 1985, fez à obra Inscrições Romanas do Conventus Pacensis, Jorge de Alarcão apontou logo algumas das ideiasmestras que viria a desenvolver pouco tempo depois no seu Roman Portugal: no volume I, em português, sintetiza, na p. 49, o que se sabe sobre Amaia (S. Salvador de Aramenha); nas pp. 50-51, sobre Aridum Vetus, que localiza no Casal da Várzea; nas pp. 99-100, aborda a problemática das vias e seus ramais identificáveis na região. O território do Nordeste abarca, no fascículo 3 do volume II desta obra, a folha 6 , onde se cartografam e sinteticamente se descrevem todos os vestígios romanos identificados até ao momento em que foi feita a correspondente pesquisa bibliográfica.

Outras publicações:

- J. Candeias da Silva elaborou comigo, em 1982, o Catálogo da Epigrafia Romana de Abrantes, área que, embora pertencente hoje ao distrito de Santarém, se insere na problemática do que foi o Nordeste durante a época romana.

- O livrinho Belver ao Tempo dos Romanos, da responsabilidade de Rogério Carvalho e minha, foi uma iniciativa da Assembleia Distrital de Portalegre, em 1984.

- O opúsculo Inscrições Romanas de Campo Maior reúne em separata os estudos publicados, em 1988, no «Ficheiro Epigráfico»;

- A pedido da Câmara Municipal de Nisa, redigi, em 1988, o opúsculo Nisa ao Tempo dos Romanos - A População e as Suas Crenças, que teve, como correspondente, para Campo Maior, o artigo A população romana de Campo Maior (Encarnação 1989).

\section{A importância dos vestígios}

É, de facto, excepcional a riqueza dos vestígios.

A sua importância documental também não padece dúvidas.

No âmbito da religião, por exemplo, detectou-se a presença de santuários (a Júpiter Repulsor em Nisa — cf. Encarnação 1977,62-65); salientou-se a importância do culto às Ninfas (IRCP 569, hoje perdido, dado como procedente da Igreja de Santa Maria, de Monforte, é o vestígio desse culto 
encontrado mais a sul no actual território nacional - cf. o artigo de Ana Caessa in "Homenagem a J. R. dos Santos Júnior", I, Lisboa, 1990,144); destacou-se a veneração a Júpiter Óptimo Máximo, em Marvão (cf. Encarnação 1981,27); sublinhou-se a persistência do apego aos deuses indígenas, de que Quangeius começa a ganhar importância significativa.. . ( $\left.{ }^{9}\right)$

No domínio político-administrativo, o juramento dos Aricienses (IRCP 647), o altar ao Génio do Ópido Constituído (IRCP 604), o testemunho do voto anual da Civitas Ammaiensis ao imperador Cláudio (IRCP 615) — são documentos epigráficos ímpares no seu género, mesmo a nível do Império.

Importará, pois, interrogarmo-nos sobre o porquê da longa fixação romana no Nordeste alentejano, sobre a organização administrativa do território, sobre as «culturas» que aí floresceram.

Longa fixação, porque ela vai desde os primeiros tempos das campanhas militares romanas $\left({ }^{10}\right)$ até ao século VI da nossa era, data, por exemplo, dos epitáfios cristãos da necrópole de Silveirona, Estremoz (Encarnação 1977, pp. 75-82).

\section{a) A organização administrativa}

No que à organização administrativa diz respeito, Jorge de Alarcão procurou definir, na obra atrás citada, os territórios das antigas cidades aqui localizadas.

Quanto a Aritium Vetus, o seu termo estender-se-ia, decerto, para a margem direita do rio Tejo, onde Maria Amélia da Horta Pereira (1970) encontrou muitos vestígios da ocupação romana, designadamente no território do actual concelho de Mação; na margem esquerda, o termo de Aritium Vetus abarcaria uma extensão sita entre o rio Tejo e as ribeiras de

$\left({ }^{9}\right)$ Identificou-se em Junho de 1991, num antiquário em Borba, uma epígrafe dedicada por C. Licinius Vegetus a este deus Quangeius, invocado sob o epíteto de Turicaecus. O culto a esta divindade no Nordeste alentejano conhecia-se desde 1981, quando se encontrara, em Salavessa (Nisa), um altar dedicado a Quangeius Tanngus (vide IRCP 641); o nome do deus, bem legível (com um Q inicial), permitiu corrigir as hipóteses de reconstituição sugeridas para outros textos fragmentários e, agora, o culto desta divindade está bastante bem documentado (Alfenim 1991).

$\left({ }^{10}\right)$ Como já tive ensejo de referir (1987, p. 168), para explicar o sentido da existência de uma grande concentração de antropónimos lusitanos dum e doutro lado do rio Tejo, Jorge de Alarcão (1985, pp. 99-100) invocou o passo de Estrabão (III, 1,6) onde se afirma que os Romanos estabeleceram Lusitanos ao Sul do Tejo, o que poderá ter ocorrido logo nos primórdios da conquista, quiçá mesmo como consequência da derrota infligida por Décimo Júnio Bruto a Lusitanos e Galaicos, em 137 a. C. 
Sor e de Nisa - mas o atraso da pesquisa aí verificado impede que outras perspectivas, mais concretas, possam, de momento, ser avançadas. Entre Agua Branca e Alter do Chão identificou-se um troço da estrada Olisipo/ Emerita.

No que concerne a Amaia, o seu território estender-se-ia, talvez, a oriente, por terrenos hoje integrados na vizinha Espanha. Os seus limites passariam, provavelmente, entre o curso do rio Sever e a ribeira de Nisa, zona onde Maria da Conceição Rodrigues (1975) anotou a presença de algumas villoe, e, a sul, na zona entre as ribeiras de Sor e da Seda, no troço mais alto dos seus percursos, onde Mário Saa (1956-1967) diz ter localizado muitas estações.

Quando é que Amaia recebeu o estatuto de município?(n) E que limites poderemos apontar, com segurança, para cada uma destas civitates?

E difícil gizar, por enquanto, uma resposta convincente. O território apontado afigura-se, porém, amplo de mais para apenas ser repartido por três civitates: Aritium Vetus, Ammaia e Emerita (que não deveria ter muito mas que abarcaria decerto, pelo menos, o termo do actual concelho de Campo Maior). Por isso, Jorge de Alarcão pergunta se não se deveria encarar seriamente a hipótese de localizar mais um aglomerado urbano romano, por exemplo em Alter do Chão (cf. também Alarcão 1990, pp. 363-364).

O já referido juramento dos Aricienses ganhou novo significado com a recente releitura (Encarnação 1989) do cipo dedicado pela Civitas Aruccitana (actual Aroche) a Agripina, mulher de Germânico e mãe de Caligula. De facto, esta homenagem póstuma (é datável do ano 37) consubstancia a extrema fidelidade regional às directrizes do Governo central, uma vez que, nos primórdios do seu reinado, foi preocupação primeira do imperador Caligula reabilitar a memória de seu pai e de sua mãe. Ora o juramento dos Aricienses data precisamente de 11 de Maio desse mesmo ano, ou seja, de escassos cinquenta e dois dias passados sobre o falecimento de Tibério.

Curiosamente, pouco tempo depois, já no reinado de Cláudio (mais precisamente em 44 ou 45), será a vez de Amaia proclamar fidelidade referindo a existência dum voto anual ao imperador, a mesma Amaia

(n) Patrick le Roux teve ensejo de chamar a atenção para a grande importância documental de que se reveste a mencionada dedicatória ao Génio do Ópido Constituído (IRCP 604): em seu entender, o oppidum aí referido «não é apenas a praça forte, mas um centro autónomo, dotado de existência própria», que não detinha, no entanto, nem o estatuto de colónia nem o de município» (1986, p. 336). Ver também, sobre o mesmo texto, Alarcão 1988,1, p. 49.

Conimbriga, 30 (1991), 23-37 
cujos munícipes dedicarão a Lúcio Vero uma estátua, em finais do ano 166 (IRCP 616):

Ocorrerá, pois, perguntar: porquê este apego ao Governo central, apego que perdura até ao século IV, como o demonstram os miliários da região?

\section{b) A cultura}

No domínio cultural, ter-se-ão em conta, por exemplo:

- a existência do culto à deusa grega Cibele numa zona aparentemente isolada (IRCP 440, Estremoz);

- o achamento dum quadrante solar numa das villo de Campo Maior (ver Cardoso 1987, p. 223);

— as representações mitológicas dos mosaicos.

Tudo isso é penhor de elevado nível cultural de mãos dadas com o elevado nível económico que os achados recentes parecem, de facto, confirmar.

Quando todo o Império parece estar em crise, o que se documenta aqui fala sobretudo de esplendor.

Um esplendor relacionável com o «renascimento» do século IV ${ }^{12}$ ?

Ou será que, de facto, «crise» foi, na verdade, um fenómeno inventado pela historiografia posterior, nomeadamente pelos escritores da chamada História Augusta do séc. IV, saudosos dos tempos em que o poder estava noutras mãos ${ }^{13}$ ?

\section{c) foco de imigração}

Voltando ao Nordeste: que razões houve para, ao tempo dos Romanos, a região ter funcionado como importante foco de imigração, mormente de clunienses, que está sobejamente documentada (cf. FE 134)?

(12) Parece provado que o chamado Édito de Galieno, de 261, que determinou o afastamento dos senadores do exercício dos cargos militares ( «Senatum militia vetuit et adire exercitum», escreve Aurélio Vítor, Caes, 33, 34) é sintoma de que os "aristocratas" se interessavam, então, mais pela «voluptuosidade do ócio", para usarmos ainda uma expressão de Aurélio Vítor (ibidem), do que pelas coisas militares. Esse «ócio» corresponde a uma atenção maior aos fenómenos culturais, porque os senadores, afastados pelas circunstâncias da ribalta da política, ora nas mãos dos militares, procuram poder social exactamente através da cultura. Daí que nas suas villoe os motivos da mitologia pagã sejam frequentemente evocados nos mosaicos; daí que, como salientou V. Neri (1981), a epigrafia latina do século IV dê particular relevo ao elogio da cultura e das virtudes políticas. Jean Gagé (1971, p. 262) fala mesmo «duma espécie de primeiro renascimento clássico e pagão».

(13) Chegou a atribuir-se, por exemplo, ao tempo de Alexandre Severo (222-235), uma recuperação do poder dos senadores, mediante nomeadamente o esta- 
Que riqueza aqui se encontraria: a pecuária (de que o mosaico dos cavalos de Torre de Palma é bom indício)? A exploração mineira? (recordem-se as referências ao aurifer Tagus...) A excelência da produção agrícola (de que os olivais seriam, ainda hoje, um bom sintoma)?

E que gentes por aqui estanciaram, então? Os estudos antroponímicos já nos deram bastantes pistas; os estudos antropológicos foram iniciados e decerto teremos para muito breve as suas conclusões.

\section{Perspectivas da futura investigação}

Por conseguinte, se quiséssemos, em síntese, apontar perspectivas para a futura investigação, diríamos, em primeiro lugar, que importa completar Roman Portugal, que é, como frisei, mais um ponto de partida do que um ponto de chegada. De facto, as sínteses atrás citadas postulam, neste momento, novas análises. Impõe-se:

1 - Completar o levantamento arqueológico sistemático de cada um dos concelhos, tendo em vista a correcta caracterização dos sítios. Preconiza-se:

a) a determinação do perímetro das villae e das necrópoles;

b) o estabelecimento do traçado das vias romanas mediante a cartografia dos indícios existentes;

c) a identificação, o mais possível exacta, do local de proveniência das peças guardadas em museus e colecções particulares.

belecimento do consilium principis em que os senadores desempenhariam papel primordial. Mas Jean Gagé (1971, p. 250) considera que este «triunfo» não passa de um desejo nascido dos biógrafos pertencentes ao círculo que, precisamente no século IV, tentava fazer renascer em tomo dos senadores as antigas tradições.

Vai no mesmo sentido a opinião de Anne Gaden (1976) e a de François Paschoud, que vê na Historia Augusta a «expressão dos sonhos de uma minoria em vias de desaparecer, uma espécie de busca do tempo perdido» (1988, p. 168).

E não será, decerto, despropositado citar aqui a referência à «mentalidade imperial» que - embora noutro contexto —é atribuída ao proprietário da já referida villa áulica de São Cucufate :«[...] uma "mentalidade imperial”, feita de distância em relação àqueles que recebia - não é verdade que ele toma assento com a família na zona absidal da aula basilical? - mentalidade que radica no fausto das recepções numa sala de jantar particularmente espaçosa e que brota sobretudo da vontade de tomar posse, através do olhar, das suas terras», com cujas colheitas poderá abastecer Pax Iulia, mentalidade imperial que, «portanto, também ganha expressão mediante o seu poder económico e a sua cupiditas adcumulandi» (Alarcão etalii 1990, p. 297). 
2 - Dar prioridade não a escavações (a não ser que se revistam de carácter de emergência) mas à intransigente salvaguarda dos sítios e vestígios encontrados.

3 - No âmbito da investigação, é tarefa urgente a inventariação e estudo dos objectos já recolhidos, de modo a poderem propor-se cronologias que complementem os dados adquiridos através da epigrafia. A publicação desses estudos e de monografias dos sítios bem como das novas perspectivas de síntese daí decorrentes possibilitará a elaboração, com mais rigor científico, de desdobráveis (didácticos e de prestígio) que proclamem, aquém e além fronteiras, a grande importância histórico-cultural da presença romana no Nordeste alentejano.

\section{BIBLIOGRAFIA}

Abreviaturas utilizadas

AP «O Arqueólogo Português», Museu Nacional de Arqueologia, Lisboa.

FE «Ficheiro Epigráfico», suplemento da Revista «Conimbriga», Instituto de Arqueologia da Faculdade de ${ }^{\wedge}$ Letras de Coimbra, Coimbra.

IA «Informação Arqueológica», Departamento de Arqueologia do Instituto Português do Património Cultural, Lisboa.

IRCP EnCarnação (José d'), Inscrições Romanas do Conventus Pacensis. Coimbra, 1984. (O número identifica a inscrição).

Alarcão (Jorge de), Sobre a romanização do Alentejo e do Algarve. A propósito de unia obra de José d'Encarnação, «Arqueologia» 111985 99-111.

Alarcão (J. de), Roman Portugal, Warminster, 1988. (Dois volumes, dos quais o I foi traduzido em português, e o II, dividido em 3 fascículos, é bilingue).

Alarcão (Jorge de), O Domínio Romano em Portugal, Mem Martins, 1988. (Versão portuguesa do I vol. de Roman Portugal).

Alarcão (Jorge de) (coordenação), Portugal - das Origens à Romanização, I volume da Nova História de Portugal, Lisboa, 1990.

Alarcão (Jorge de), Étienne (Robert)* e MAYet (Françoise) (direcção), Les Villas Romaines de São Cucufate (Portugal), Paris, 1990.

Alfenim (Rafael A. E.), Ex-voto a Quangeio Turicaeco, FE 381991 n. ${ }^{\circ} 174$.

Cardoso (Guilherme), Quadrante solar romano de Freiría (S. Domingos de Rana, Cascais), AP série IV 5 219-224.

Carvalho (Rogério), Uma placa funerária de Campo Maior, FE 251988 n. 113. CARvalho (Rogério), Miliàrio de Campo Maior, FE 251988 n. ${ }^{\circ} 11$.

EnCARnaÇão (José d'), Epigrafia romana do Nordeste alentejano —Nisa, Torre de Palma e Silveirona, «Conimbriga»16 1977 59-82. 
ENCARnaÇão (José d'), A religião romana não-oficial nas colónias e municípios da Lusitânia durante o Alto Império, «Memorias de Historia Antigua» 5198119-31 .

EnCARnaÇão (José d'), A população romana do Nordeste alentejano, «l. ${ }^{\text {as }}$ Jornadas de Arqueologia do Nordeste Alentejano - Actas», Castelo de Vide, 1987, 167-170.

Encarnação (José d'), Nisa ao tempo dos Romanos - A População e as Suas Crenças, Câmara Municipal de Nisa, 1988.

Encarnação (José d'), Miliàrio de Severo Alexandre em Campo Maior, FE 251988 n. ${ }^{\circ} 115$.

ENCARNAÇÃo (José á'), Estela funerária deAramenha, «Conimbriga»161977 59-82.

EnCARNAÇÃo (José d'), Uma homenagem a Agripina, mulher de Germànico, «Conimbriga» 281989 157-167.

Encarnação (José d'), A população romana de Campo Maior, «Trabalhos de Antropologia e Etnologia» 291989 83-94.

Encarnação (José d') e Carvalho (Rogério), Belver ao Tempo dos Romanos, Assembleia Distrital de Portalegre, 1984.

EncarnaÇão (José d') e Silva (J. Candeias), Catálogo da epigrafia romana de Abrantes, «Abrantes» 11982 21-38.

Fernandes (Isabel Cristina F.), Espólio da necrópole dos Pombais, «1. ${ }^{\text {as }}$ Jornadas de Arqueologia do Nordeste Alentejano - Actas», 1987,101-116.

Ferreira (A. M. Brazão) - Vide Valente.

Frade (Helena) e CaEtano (José Carlos), A necrópole romana da Laje do Ouro (Aldeia da Mata, $\mathrm{Cr}$ ato), «l. as Jornadas de Arqueologia do Nordeste Alentejano - Actas», 1987, 133-143.

Frade (Helena) e CAETANo (José Carlos), Ritos funerários romanos no Nordeste alentejano, «II Congresso Peninsular de História Antiga - Actas», Coimbra, no prelo.

Gaden (Anne), Structure et portée historique de la Vie d'Hadrien dans l'Histoire Auguste, «Ktema» 11976 129-144.

Gagé (Jean), Les Classes Sociales dans l'Empire Romain, Paris, ${ }^{2} 1971$.

Heleno (Manuel), Notas sobre algumas estações da época lusitano-romana, AP $\mathrm{n}$. s. 21953 257-260.

Heleno (Manuel), A «villa» lusitano-romana de Torre de Palma (Monforte), AP n. s. 41962 313-338.

Kuznetsova-Resende (Tatiana), O mosaico com motivos báquicos de Torre de Palma: tentativa de interpretação, «Conimbriga» 281989 205-221.

LE Roux (Patrick), Municipe et droit latin en Hispania sous l'Empire, «Revue Historique de Droit Français et Étranger» 64 1986 325-350.

NERI (V.), L'elogio della cultura e l'elogio delle virtù politiche nell'epigrafia latina del TV secolo d. C., «Epigraphica» 431981 175-201.

Nolen (Jeannette U. Smit), Cerâmica Comum de Necrópoles do Alto Alentejo, Lisboa, 1985.

Paschoud (François), La Storia Augusta come testimonianza e riflesso della crisi d'identità degli ultimi intellettuali pagani in Occidente, «I Cristiani e T Impero 
nel IV Secolo», Colloquio sul Cristianesimo nel Mondo Antico, a cura di Giorgio Bonamente e Aldo Nestori, Macerata, 1988, 155-169.

Patrimònio Arqueológico do Alentejo - Plano de Conservação e Valorização a Médio Prazo, documento policopiado, da responsabilidade do Serviço Regional de Arqueologia da Zona Sul, Évora, 1990.

Pereira (M. Amélia Horta), Monumentos Históricos do Concelho de Mação, Mação, 1970.

Ponte (Sálete da), Algumas fibulas de Torre de Palma (Monforte), «1. ${ }^{\text {as }}$ Jornadas de Arqueologia do Nordeste Alentejano - Actas», 1987, 117-121.

Quíntela (António de Carvalho), CARdoso (João Luís) e Mascarenhas (José Manuel), Aproveitamentos Hidráulicos Romanos a Sul do Tejo (Contribuição para a Sua Inventariação e Caracterização), Lisboa, 1986.

Rodrigues (M.â Conceição Monteiro), Carta Arqueológica do Concelho de Castelo de Vide, Lisboa, 1975.

SAA (Mário), As Grandes Vias da Lusitânia (O Itinerário de Antonino Pio), Lisboa, 1 1956, II 1959, III 1960, IV 1963, V 1964, VI 1967.

Silva (José Rafael Correia da) e Encarnação (José d'), Uma placa monumental de Ponte de Sor, FE 361990 n. 162.

SimÕes (Maria Helena), Vidros romanos do Museu do $\mathrm{Cr}$ ato, «l. as Jornadas de Arqueologia do Nordeste Alentejano - Actas», 1987,123-125.

Valente (M. F. F.), Lourenço (F. S.), Barreto (M. R. S.) e Ferreira (A. M. Brazão), Arqueologia romana do concelho de Alter do Chão - Subsídios para o seu estudo, «Actas das III Jornadas Arqueológicas 1977», 1, Lisboa, 1978, 275-292 . 


\section{EST. I}

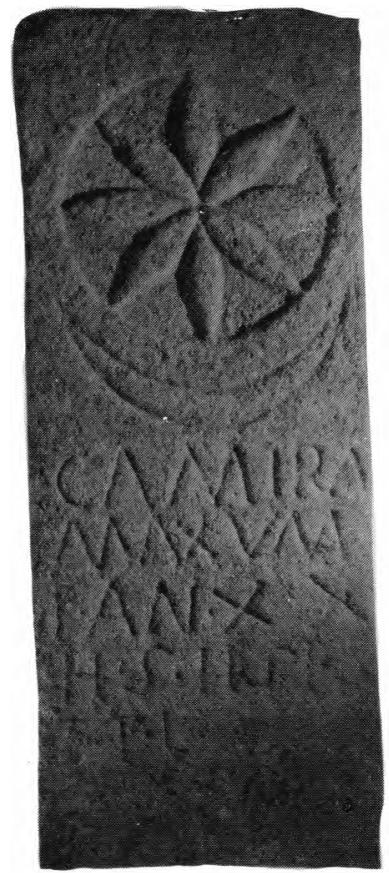

FIG. 1

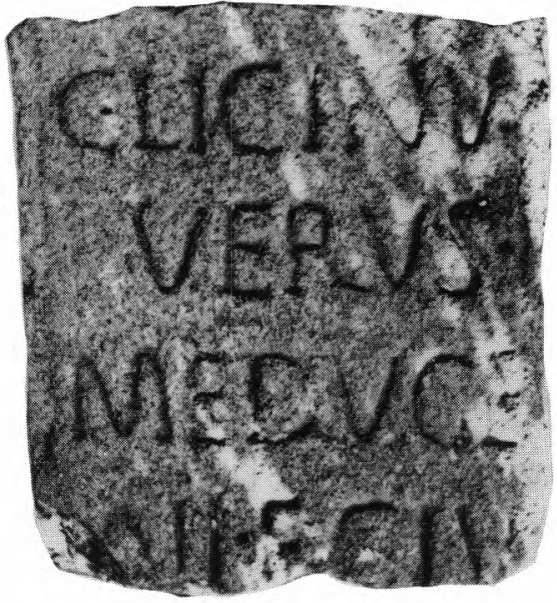

FIG. 2

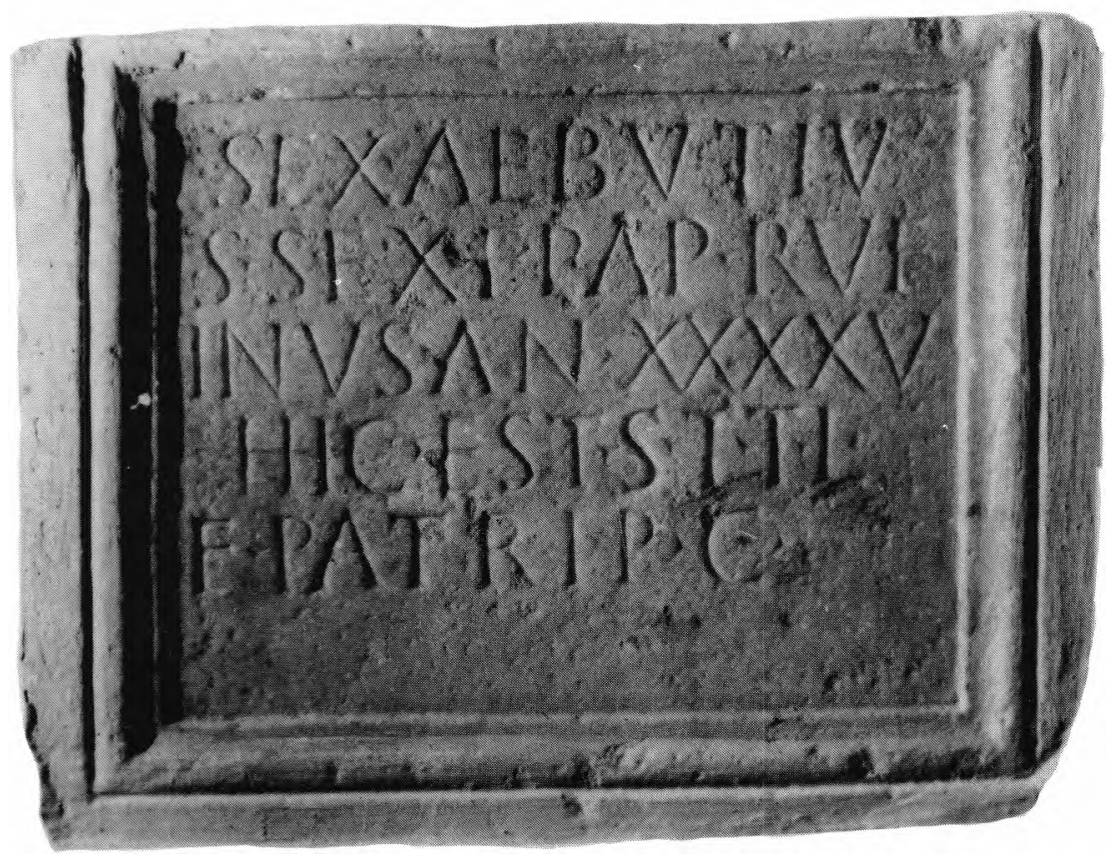

FIG. 3 
EST. II
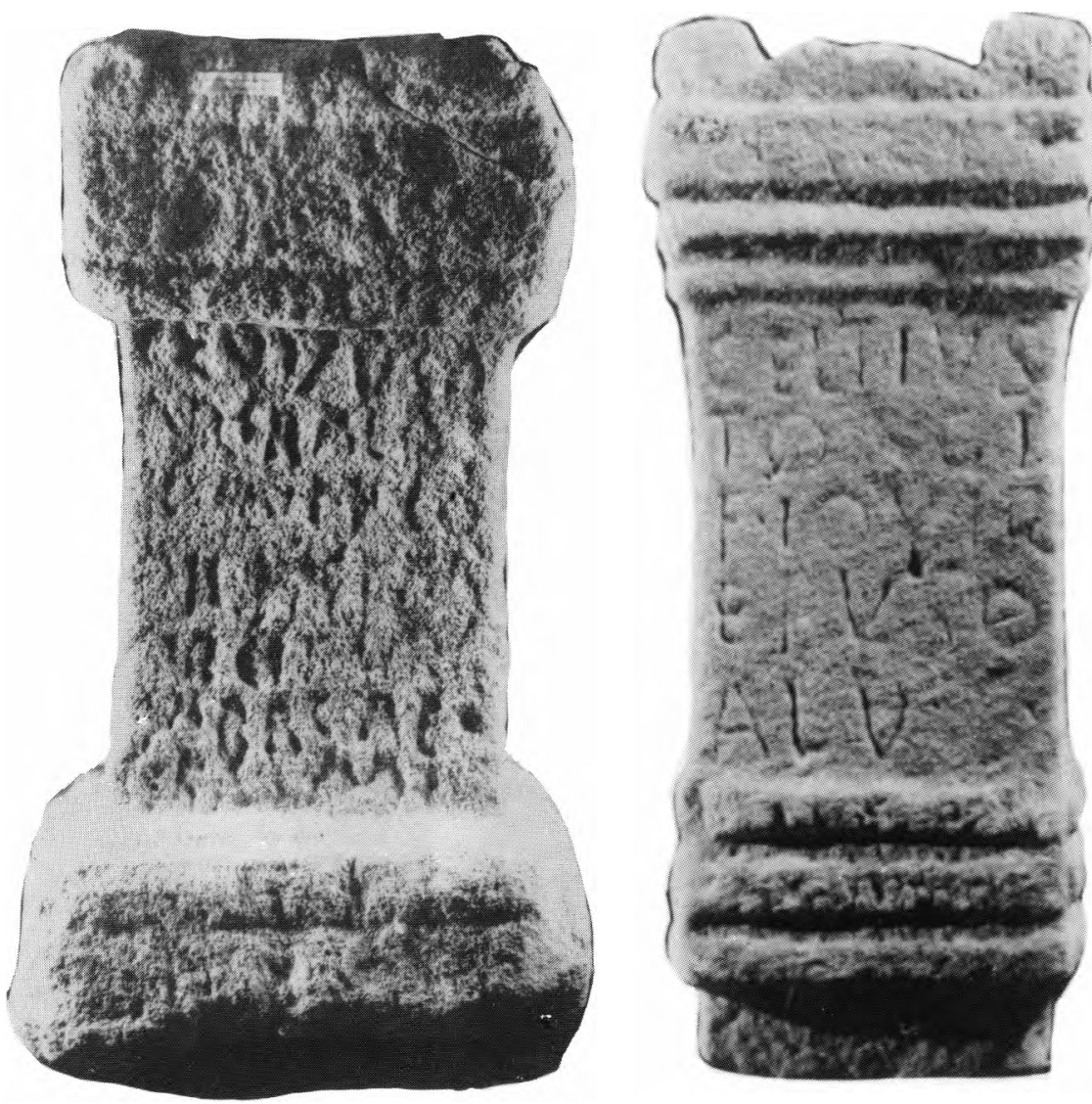

FIG. 1

FIG. 2 
EST. IIl

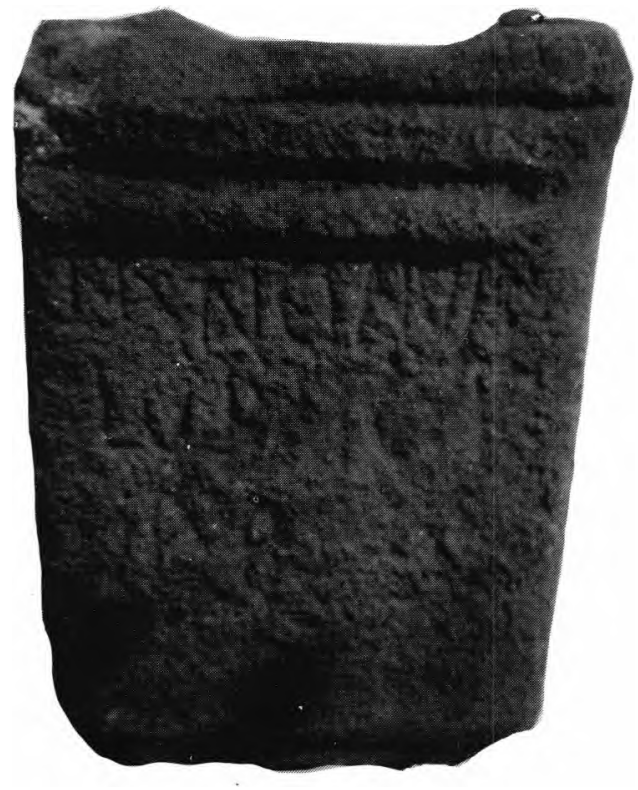

FIG. 3 